\title{
Back to Back Voltage Source Inverter untuk Kontrol Self Excited Induction Generator
}

\author{
Ainur Rachmad Hidayat, Dedet Candra Riawan, dan Mochamad Ashari \\ Teknik Elektro, Fakultas Teknologi Industri, Institut Teknologi Sepuluh Nopember (ITS) \\ J1. Arief Rahman Hakim, Surabaya 60111 \\ Email: dedet@ee.its.ac.id, dan ashari@ee.its.ac.id
}

\begin{abstract}
Abstrak --- Angin merupakan salah satu energi terbarukan yang sangat pesat perkembangannya dalam membantu memenuhi kebutuhan energi listrik seiring ketersediaannya yang melimpah. Alat yang bisa digunakan untuk mengubah energi angin menjadi energi listrik adalah generator induksi. Pada tugas akhir ini akan membahas operasi turbin angin dengan generator induksi dikontrol menggunakan back to back voltage source inverter serta sistem terhubung jaringan listrik tiga fasa tegangan rendah $(380 \mathrm{~V})$. Pensaklaran back to back voltage source inverter dimodelkan dalam bentuk average model. Pada back to back voltage source inverter terdapat dua konverter yaitu konverter sisi mesin (machine side converter) dan konverter sisi grid (grid side converter). Konverter sisi mesin berfungsi untuk mengatur tegangan dan frekuensi serta pengaturan kecepatan turbin agar turbin angin dapat menghasilkan daya maksimum (maximum power point tracking) dengan metode kontrol volt/hetrz constant. Konverter sisi grid berfungsi untuk mengatur tegangan DC agar tetap konstan dengan mensinkronkan sudut fasa antara keluaran konverter dan grid dengan menggunakan metode current controlled voltage source inverter. Hasil simulasi menunjukkan bahwa daya yang dihasilkan turbin angin selalu maksimum pada setiap kecepatan angin. Tegangan dan frekuensi generator menjadi stabil dan berbanding lurus dengan kecepatan angin serta tegangan de link selalu konstan sehingga dapat mengalirkan daya secara dua arah. Oleh karena itu back to back voltage source inverter sangat cocok digunakan untuk pengontrolan turbin angin dengan menggunakan generator induksi.
\end{abstract}

Kata Kunci --- Turbin Angin, Konverter Sisi Mesin, Konverter Sisi Grid, Volt/Hertz konstan, DC-Link, Current Controlled Voltage Source Inverter, Average Model.

\section{PENDAHULUAN}

$\mathrm{D}$ EWASA ini, banyak terdapat perusakan lingkungan yang disebabkan oleh bahan bakar fosil. Oleh karena itu, perlu dikembangkannya teknologi - teknologi pembangkitan listrik dari energi terbarukan yang ramah lingkungan dan dapat langsung dimanfaatkan seiring ketersediannya yang melimpah. Salah satu sumber energi terbarukan yang dapat dimanfaatkan untuk menghasilkan listrik adalah energi angin. Alat yang digunakan untuk mengubah energi angin menjadi energi listrik adalah generator induksi.

Pada umumnya, Generator induksi dapat dioperasikan menggunakan dua sistem yaitu sistem stand alone biasanya diterapkan pada daerah yang tidak terjangkau jaringan listrik dan sistem grid connected (terhubung dengan jaringan) yang biasanya diterapkan pada daerah yang terdapat jaringan listrik. Pada operasi stand alone tegangan dan frekuensi keluaran generator induksi sangat sensitif terhadap perubahan beban. Hal ini akan menyebabkan tegangan dan frekuensi keluaran yang fluktuatif [1]. Oleh karena itu perlu diadakannya pengaturan tegangan dan frekuensi keluaran generator induksi. Sedangkan pada operasi sistem grid connected diperlukan adanya kontrol untuk mengatur kecepatan turbin agar turbin angin dapat selalu menghasilkan daya maksimum pada setiap kecepatan angin serta kontrol tegangan dc link agar sistem stabil dan dapat mengalirkan daya secara dua arah.

Pada tugas akhir ini akan membahas operasi turbin angin dengan sistem grid connected dan dikontrol menggunakan back to back voltage source inverter yang dimodelkan dalam average model switching. Pada back to back voltage source inverter terdapat dua konverter yaitu konverter sisi mesin (machine side converter) dan konverter sisi grid (grid side converter). Konverter sisi mesin berfungsi untuk mengatur tegangan dan frekuensi serta pengaturan kecepatan turbin agar turbin angin dapat menghasilkan daya maksimum (maximum power point tracking) dengan metode kontrol volt/hetrz constans. Konverter sisi grid berfungsi untuk mengatur tegangan DC agar tetap konstan dengan mensinkronkan sudut fasa antara keluaran konverter dan grid dengan menggunakan metode current controlled voltage source inverter [2].

\section{VARIABLE SPEED WIND ENERGY CONVERSION SYSTEM BERBASIS SEIG}

\section{A. Wind Turbine}

Energi angin adalah energi terbarukan yang saat ini sangat berkembang. Prinsip kerja dari turbin angin adalah mengubah gerak linier menjadi gerakan rotasi dan kemudian gerakan rotasi tersebut diubah menjadi energi listrik dengan generator. Daya yang dihasilkan oleh turbin angin sesuai dengan persamaan:

$P_{w}=\frac{1}{2} \rho A v_{w}^{3}$

$\rho$ adalah masa jenis udara $\left(1.225 \mathrm{~kg} / \mathrm{m}^{3}\right)$

A adalah luas turbin $\left(\mathrm{m}^{2}\right)$,

$\mathrm{r}$ adalah jari-jari turbin 
$v_{w}$ adalah kecepatan angin $(\mathrm{m} / \mathrm{s})$.

Besar daya mekanik $\left(\mathrm{P}_{\mathrm{m}}\right)$ yang dihasilkan turbin angin tergantung pada koefisien daya/power coefficient $\left(\mathrm{C}_{\mathrm{p}}\right) \cdot \mathrm{C}_{\mathrm{p}}$ adalah perbandingan antara daya aktual yang dihasilkan dari turbin angin dengan daya energi angin. $C_{p}$ menggambarkan efisiensi dari turbin angin yang nilainya berbeda pada setiap turbin angin [3]. Berikut adalah persamaan dari $\mathrm{C}_{\mathrm{p}}$ :

$P_{m}=P_{w} C_{p}(\lambda, \beta)=\frac{1}{2} \rho A v_{w}^{3} C_{p}(\lambda, \beta)$

Dimana $C_{p}(\lambda, \beta)$ adalah fungsi koefisien daya, $\lambda$ adalah tip speed ratio (TSR), dan $\beta$ adalah pitch angle.

Fungsi koefisien daya, $C_{p}(\lambda, \beta)$ tergantung pada dua faktor yaitu Tip Speed Ratio (TSR) $\lambda$ dan pitch angle $\beta$. Koefisien daya dirumuskan [7]:

$C_{p}=c_{1}\left(\frac{c_{2}}{\lambda_{i}}-c_{3} \beta-c_{4}\right) e^{-\frac{c_{5}}{\lambda_{i}}}+c_{6} \lambda$

Dimana $\mathrm{c}_{1}-\mathrm{c}_{6}$ adalah konstanta mesin pada turbin angin.

Tip Speed Ratio (TSR) merupakan perbandingan antara putaran linier dari rotor turbin dengan kecepatan angin. Berikut adalah persamaan matematis dari TSR:

$\lambda=\frac{r \omega}{v_{w}}$

Pitch angle $\beta$ merupakan sudut blade pada turbin angin terhadap sumbu longitudinalnya. Gambar 1 berikut menunjukkan kurva koefisien daya pada fixed pitch $\beta=0^{\circ}$. Dari gambar berikut dapat diketahui bahwa terdapat titik optimal koefisien daya $\left(\mathrm{C}_{\mathrm{p} \_ \text {max }}\right)$ yaitu saat TSR-nya bernilai optimal $\left(\lambda_{\text {opt }}\right)$. $\mathrm{C}_{\mathrm{p}_{\text {max }}}$ ini merepresentasikan efisiensi dari turbin angin terhadap daya mekanik yang dibangkitkannya [4].

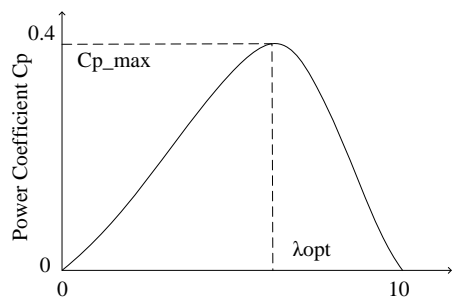

Gambar 1. Koefisien daya sebagai fungsi dari TSR

Turbin angin juga memiliki kurva karakteristik daya yang bergantung pada kecepatan angin dan pitch angle. Pada nilai pitch angle yang tetap (fixed pitch), pada gambar 2 berikut adalah kurva karakteristik daya turbin angin terhadap putaran rotornya. Besar torsi yang dihasilkan dari turbin angin adalah sebesar [3]:

$T_{m}=P_{m} \frac{r}{G \lambda v_{w}}$

Dimana $\mathrm{r}$ adalah jari-jari rotor turbin dan $\mathrm{G}$ adalah rasio gear. Pada turbin angin yang menggunakan sistem gearless atau direct driven maka tidak terdapat variabel $\mathrm{G}$.

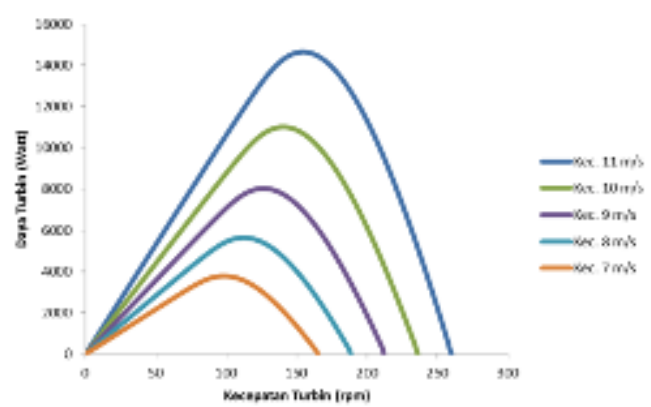

Gambar 2. Karakteristik daya terhadap putaran rotor turbin

Hubungan antar daya dan kecepatan angin sangat penting untuk kontrol maximum power point tracking pada turbin angin. Kurva diatas menunjukkan karakteristik daya yang dapat dihasilkan oleh turbin angin pada kecepatan angin yang berbeda - beda.

\section{B. Self Excited Induction Generator}

Generator induksi penguatan sendiri adalah generator induksi yang menggunakan kapasitor yang di paralelkan di sisi stator generator tersebut. Berikut adalah rangkaian steady state generator induksi penguatan sendiri [5]:

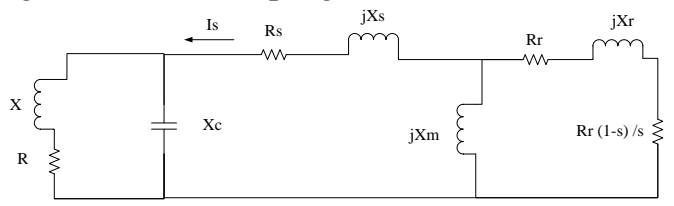

Gambar 3. Rangkaian steady state generator induksi penguatan sendiri

Pada bagian stator, rotor dan magnetisasi direpresentasikan:

$Y s=\operatorname{Re}(Y s)+\operatorname{Im}(Y s)$

$\operatorname{Re}(Y s)+\frac{\frac{R r}{s}}{\left(\frac{R r}{s}\right)^{2}+(w X r)^{2}}=0$

$\operatorname{Im}(Y s)+\frac{w X r}{\left(\frac{R r}{s}\right)^{2}+(w X r)^{2}}+\frac{1}{w X m}=0$

Arus eksitasi generator induksi penguatan sendiri berasal dari kapasitor yang dirangkai paralel dengan stator mesin. Kapasitor berfungsi memberikan daya reaktif pada generator. Ketika generator diputar oleh prime mover sampai kecepatan putar rotor berada diatas kecepatan putar rating mesin induksi pada stator, maka akan timbul tegangan, namun tegangan yang timbul nilainya relatif kecil [6]. Oleh karena itu, pada saat itu fungsi dari kapasitor dibutuhkan sebagai sumber daya reaktif. Hubungan antara tegangan generator dan kapasitor ditunjukkan pada gambar Gambar 4. 


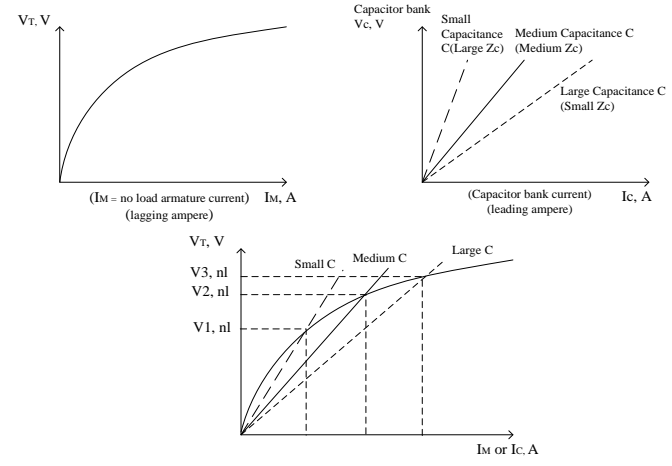

Gambar 4. Kurva magnetisasi self excited induction generator

\section{Current Controlled Voltage Source Inverter menggunakan} Average Model

Current Controlled berfungsi untuk mengontrol arus keluaran voltage source inverter agar sesuai dengan yang diinginkan. Agar arus keluaran voltage source inverter dapat diatur sesuai dengan tegangan dan frekuensi sistem maka dilakukan teknik penskalaran yang dalam tugas akhir ini dimodelkan dalam average model. Average model menggunakan rangkaian terpisah antara sisi DC dan AC.

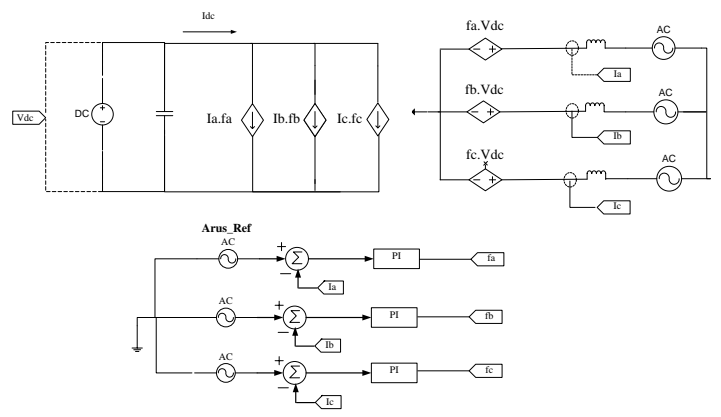

Gambar 5. Diagram blok kontrol current controlled voltage source inverter menggunakan average model.

Persamaan tegangan dan arus pada average model adalah sebagai berikut:

$\left[\begin{array}{l}f_{a b} \\ f_{b c} \\ f_{c a}\end{array}\right]=\left[\begin{array}{c}f_{m} \cos (w t) \\ f_{m} \cos \left(w t-120^{\circ}\right) \\ f_{m} \cos \left(w t+120^{\circ}\right)\end{array}\right]$

$\left[\begin{array}{l}V_{a b} \\ V_{b c} \\ V_{c a}\end{array}\right]=\left[\begin{array}{l}f_{a b} \\ f_{b c} \\ f_{c a}\end{array}\right] x V_{d c}$

$I_{d c}=\left[\begin{array}{lll}f_{a b} & f_{b c} & f_{c a}\end{array}\right] x\left[\begin{array}{l}I_{a b} \\ I_{b c} \\ I_{c a}\end{array}\right]$

$V a b=m_{a} \times \sqrt{3} \times \frac{V_{d c}}{2}, 0<m_{a} \leq 1$

$\mathrm{Vab}$ : Tegangan keluaran line to line inverter

$\mathrm{m}_{\mathrm{a}}$ : Indeks Modulasi

$\mathrm{V}_{\mathrm{dc}}$ : Tegangan masukan inverter

\section{VOLT/HERTZ CONSTANT CONTROL}

Pengatuaran kecepatan motor induksi sangat dibutuhkan dalam dunia industri. Salah satu jenis kontrol yang digunakan untuk mengontrol kecepatan mesin induksi atau yang biasanya disebut dengan variable speed drive (VSD). Pada variable speed drive metode yang digunakan untuk mengontrol kecepatan mesin induksi adalah kontrol volt/hertz.

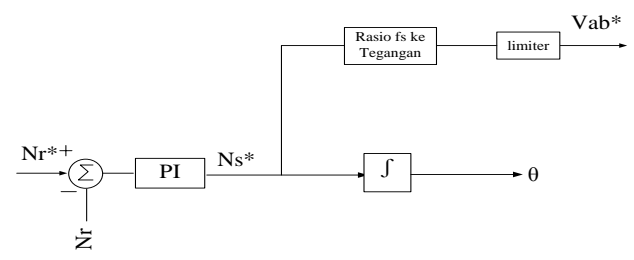

Gambar 6. Skema kontrol volt/hertz constant

Dari skema kontrol pada gambar Gambar 6 terlihat bahwa tegangan mesin induksi berbanding lurus dengan frekuensi. Pada saat kecepatan putar rotor referensi naik maka frekuensi stator naik maka tegangan mesin induksi juga akan naik dan sebaliknya. Akan tetapi pada gambar 6 terdapat sebuah limiter yang berfungsi untuk membatasi tegangan referensi dari mesin induksi. Tegangan maksimum dari mesin induksi adalah tegangan rating dari mesin induksi tersebut.

\section{BACK TO BACK VSI UNTUK WIND ENERGY CONVERSION SYSTEM BERBASIS SEIG}

\section{A. Konfigurasi Sistem Back to Back Voltage Source Inverter untuk Kontrol Self Excited Induction Generator}

Sistem back to back voltage source inverter terdiri dari beberapa bagian yaitu turbin angin untuk menghasilkan daya mekanis, gearbox untuk menaikkan kecepatan agar sesuai dengan rating generator, SEIG untuk mengkonversi daya mekanis ke elektris, konverter sisi mesin, konverter sisi grid pengontrol tegangan DC link dan Impedansi L yang menghubungan ke jala - jala. Pada sistem back to back voltage source inverter energi listrik yang dihasilkan turbin angin akan langsung disalurkan ke jala - jala tegangan rendah (grid connected).

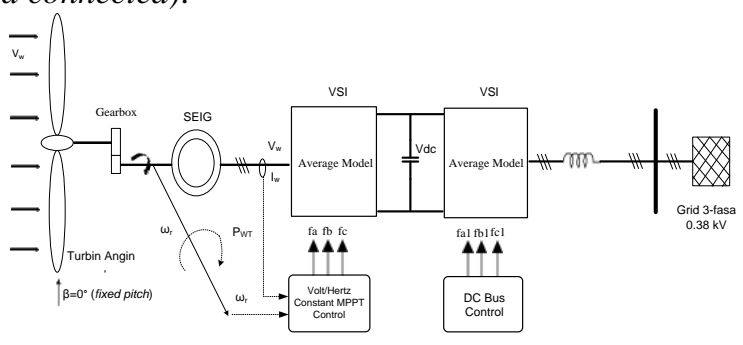

Gambar 7. Skema total sistem back to back VSI

\section{B. Model Wind Turbine}

Turbin angin yang digunakan pada penelitian ini menggunakan mode operasi variable speed dan fixed pitch angle. Turbin angin dihubungkan dengan generator SEIG menggunakan gearbox sehingga sistem turbin angin ini adalah undirect driven.

- Kecepatan rating generator : $1800 \mathrm{rpm}$

- Kecepatan rating turbin angin $(11 \mathrm{~m} / \mathrm{s}): 155 \mathrm{rpm}$ 
- Gearbox: $\frac{1800}{155}=11,612$

Turbin angin yang digunakan adalah Kingspan berdaya rating $15 \mathrm{~kW}$ pada kecepatan angin $11 \mathrm{~m} / \mathrm{s}$. Datasheet dari turbin angin Kingspan ditunjukkan pada tabel 1 berikut:

Tabel 1. Parameter Turbin Angin Kingspan

\begin{tabular}{ll}
\hline \multicolumn{1}{c}{ Parameter } & \multicolumn{1}{c}{ Nilai } \\
\hline Daya & $15 \mathrm{kw}$ \\
Daya maksimum & $15,7 \mathrm{kw}$ \\
Power Coefficient $(\mathrm{Cp})$ & 0,244 \\
Tip Speed Ratio $(\mathrm{TSR})$ & 4,8 \\
Kecepatan angin Cut-In & $3,5 \mathrm{~m} / \mathrm{s}$ \\
Kecepatan angin Rated & $11 \mathrm{~m} / \mathrm{s}$ \\
Kecepatan angin Cut-Out & Continous Operation \\
Survival Wind Speed & $70 \mathrm{~m} / \mathrm{s}$ \\
Blade Pitch Control & None, Fixed Pitch \\
Jari-jari turbin & $4,9 \mathrm{~m}$ \\
Kecepatan rotor & $155 \mathrm{rpm}$ \\
Jumlah blade & 3 \\
\hline \hline
\end{tabular}

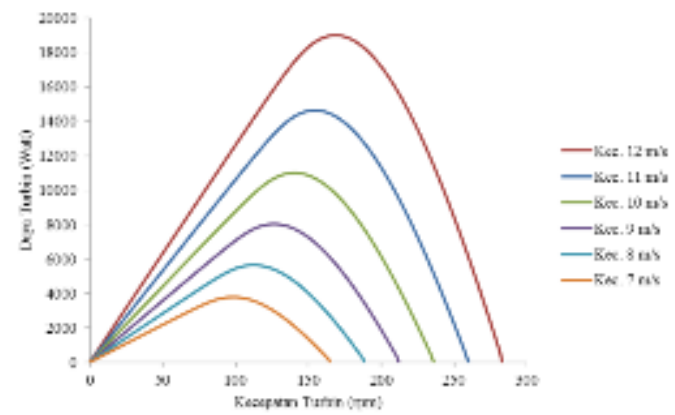

Gambar 8. Hasil pengujian karakteristik turbin angin Kingspan

\section{Parameter Generator Induksi}

Tabel 2. Parameter Generator Induksi

\begin{tabular}{ll}
\multicolumn{1}{c}{ Parameter } & \multicolumn{1}{c}{ Nilai } \\
\hline \hline Jumlah pasang kutub & 4 \\
Daya & $18,65 \mathrm{~kW}$ \\
Resistansi stator (Rs) & $0,641 \mathrm{ohm}$ \\
Reaktansi stator (Ls) & $2,935 \mathrm{mH}$ \\
Resistansi rotor (Rr) & $0,332 \mathrm{ohm}$ \\
Reaktansi rotor (Lr) & $1,231 \mathrm{mH}$ \\
Reaktansi Magnetisasi (Lm) & $69,798 \mathrm{mH}$ \\
Inersia & $0,2 \mathrm{~kg} \cdot \mathrm{m}^{2}$ \\
\hline \hline
\end{tabular}

\begin{tabular}{ll}
\hline \hline Tegangan operasi & 460 Volt \\
Frekuensi & $60 \mathrm{~Hz}$ \\
\hline \hline
\end{tabular}

\section{D.Back To Back Voltage Source Inverter}

Sistem back to back VSI terdiri dari dua konverter yaitu konverter sisi grid dan konverter sisi mesin.

\section{1) Grid Side Converter}

Grid side converter digunakan untuk mengontrol tegangan dc link agar tetap konstan sesuai dengan referensi. Pada grid side converter terdapat dua buah kontrol loop yaitu outer loop dan inner loop. Outer loop control digunakan untuk mengatur tegangan dc pada dc-link agar selalu bernilai konstan pada tegangan referensi tertentu. Sedangkan inner loop digunakan untuk mengontrol besar arus yang akan disalurkan ke jaringan. Pada inner loop, sinyal input berupa arus inverter yang yang kemudian dibandingkan dengan arus referensi dengan metode current control[1].

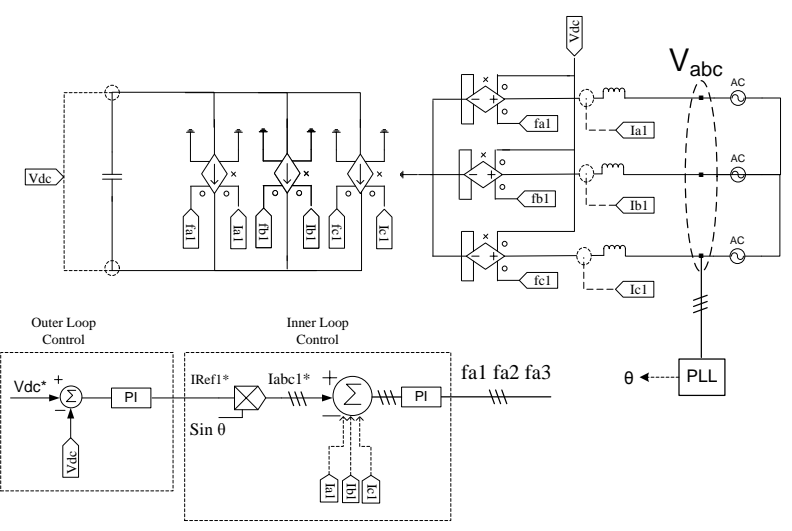

Gambar 9. Rangkaian kontrol voltage source inverter (VSI) tiga fasa grid side converter

\section{2) Machine Side Converter}

Machine side converter digunakan untuk mengotrol kecepatan putar generator yang disambungkan dengan turbin angin agar turbin angin selalu menghasilkan daya maksimum pada setiap kecepatan angin. Metode yang digunakan untuk mengontrol kecepatan putar generator adalah menggunakan metode kontrol volt/hertz konstan yang dijelaskan pada bab sebelumnya atau pada gambar 6. Pada metode ini pengontrolan kecepatan generator dilakukan dengan cara mengontrol tegangan dan arus pada generator induksi. Pada kontrol pada konverter sisi mesin juga terdiri dari dua kontrol yaitu outer loop control untuk mengontrol kecepatan dan tegangan generator induksi serta inner loop control yang digunakan untuk mengontrol arus pada generator. 


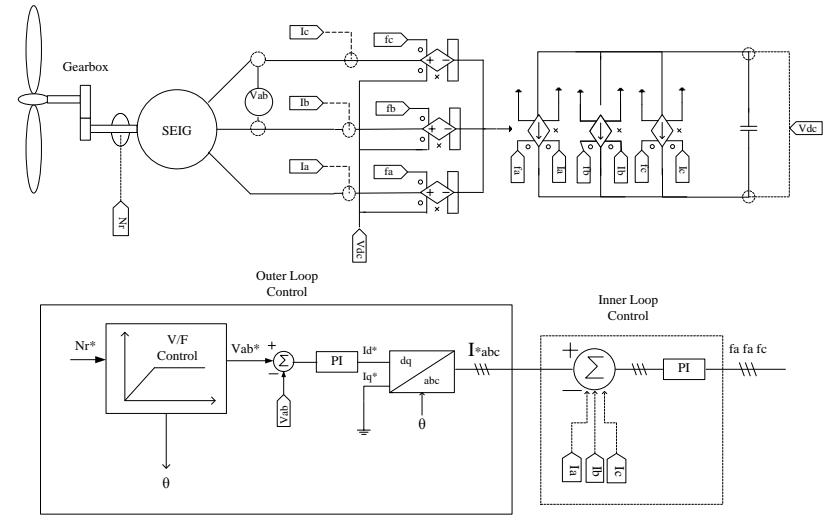

Gambar 10. Rangkaian kontrol voltage source inverter (VSI) tiga fasa machine side converter

\section{SIMULASI DAN ANALISIS}

\section{A. Simulasi Keadaan steady state turbin angin}

Pada simulasi ini turbin angin dioperasikan pada kecepatan angin konstan yaitu pada $3,5 \mathrm{~m} / \mathrm{s}$ dan $11 \mathrm{~m} / \mathrm{s}$.

1) Operasi pada kecepatan angin $3,5 \mathrm{~m} / \mathrm{s}$

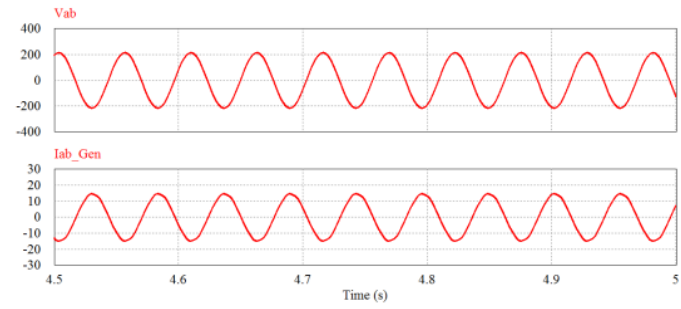

Gambar 11. Tegangan dan arus generator

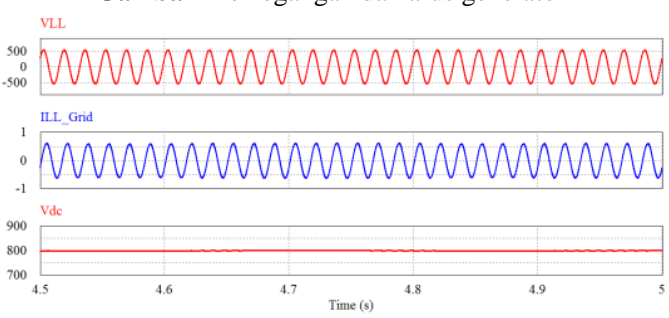

Gambar 12. Tegangan dan arus generator serta tegangan dc link

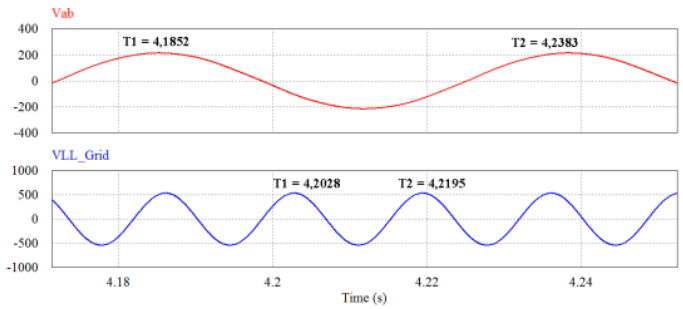

Gambar 13. Frekuensi generator dan VSI grid

Pada gambar diatas terlihat bahwa pada kecepatan angin yang konstan tegangan dan arus generator dan VSI grid bernilai konstan. Tegangan dc link juga stabil pada 800 Volt. Akan tetapi nilai frekuensi generator dan VSI grid berbeda yaitu $18,87 \mathrm{~Hz}$ untuk generator dan $60 \mathrm{~Hz}$ untuk grid. Hal ini disebabkan karena frekuensi generator tergantung pada kecepatan angin, sedangkan frekuensi grid dikontrol agar tetap konstan $60 \mathrm{~Hz}$.
2) Operasi pada kecepatan angin $11 \mathrm{~m} / \mathrm{s}$

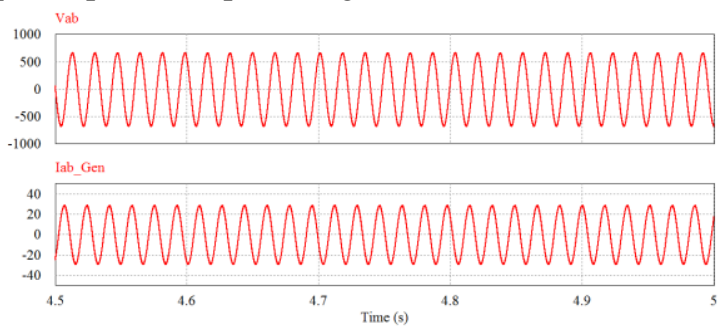

Gambar 14. Tegangan dan arus generator

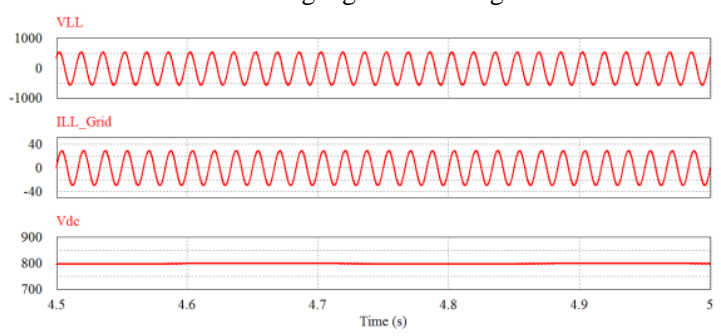

Gambar 15. Tegangan dan arus VSI grid serta tegangan dc link

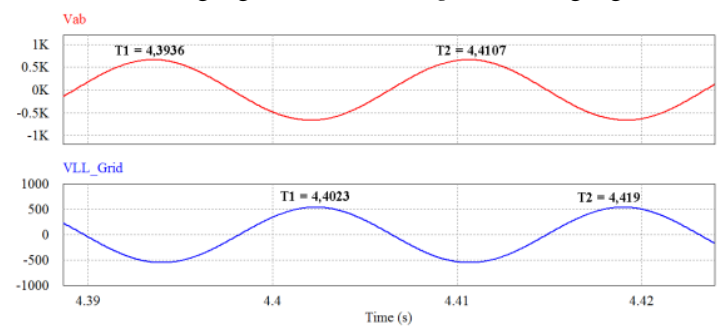

Gambar 16. Frekuensi generator dan VSI grid

Pada gambar diatas terlihat bahwa nilai tegangan dan arus generator serta VSI grid konstan. Frekuensi generator pada gambar diatas didapat 58,48 Hz dan VSI grid tetap $60 \mathrm{~Hz}$. Pada kecepatan angin yang lebih tinggi nilai parameter diatas semakin naik juga semakin naik.

\section{B. Simulasi keadaan dinamik turbin angin}

Pada simulasi kecepatan angin yang digunakan adalah mulai dari $3,5 \mathrm{~m} / \mathrm{s}$ naik sampai $11 \mathrm{~m} / \mathrm{s}$.

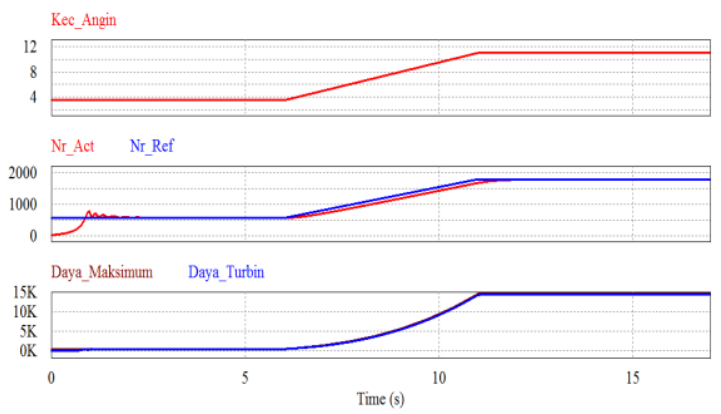

Gambar 17. Kurva kecepatan dan daya turbin angin

Tabel 3. Perbandingan daya aktual dan daya maksimum turbin angin

\begin{tabular}{llllll}
\hline \hline $\begin{array}{l}\text { Kecepatan } \\
\text { Angin }(\mathrm{m} / \mathrm{s})\end{array}$ & $\begin{array}{l}\text { Daya } \\
\text { Turbin } \\
\text { (Watt) }\end{array}$ & $\begin{array}{l}\text { Aktual } \\
\text { Angin }\end{array}$ & $\begin{array}{l}\text { Daya } \\
\text { Maksimum } \\
\text { Turbin (Watt) }\end{array}$ & $\begin{array}{l}\text { Efisiensi } \\
(\%)\end{array}$ & Tracking \\
\hline 3,5 & 470 & & 475 & 99 \\
11 & 14594 & & 14639 & 99,7 \\
\hline \hline
\end{tabular}


Dari tabel diatas terlihat bahwa maksimum didapatkan nilai efisiensi tracking turbin angin yaitu $99 \%$ untuk kecepatan angin 3,5 m/s dan 99,7 \% untuk kecepatan angin $11 \mathrm{~m} / \mathrm{s}$. Sedangkan kecepatan generator aktual mempunyai nilai yang sama dengan kecepatan generator referensi.

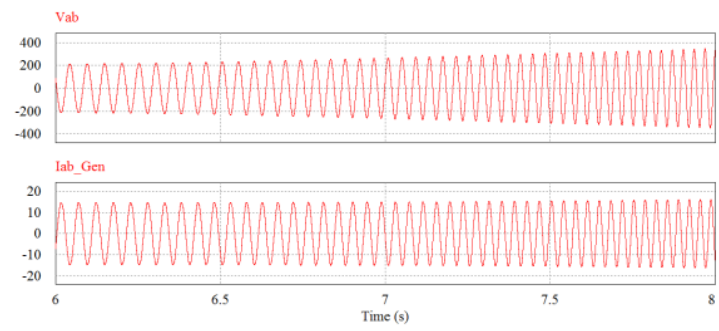

Gambar 18. Tegangan dan arus generator

Terlihat dari gambar 18 apabila kecepatan angin naik maka nilai tegangan dan arus juga akan naik. Hal ini disebabkan apabila kecepatan angin naik maka kecepatan putar generator juga semakin naik dan menyebabkan tegangan referensi juga naik karena kontrol volt/hertz konstan.

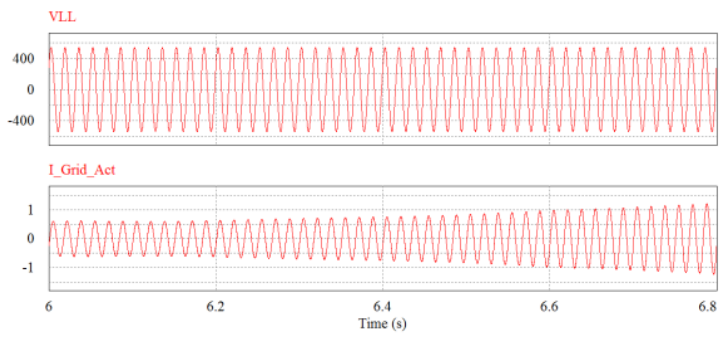

Gambar 19. Tegangan dan Arus VSI grid

Dari gambar diatas terlihat bahwa nilai tegangan VSI grid relatif konstan meskipun terjadi kenaikan kecepatan angin. Hal ini dikarenakan indeks modulasi harus dijaga tetap kurang dari 1. Sedangkan semakin tinggi kecepatan angin maka arus VSI grid semakin besar karena daya yang dihasilkan turbin angin juga semakin besar.

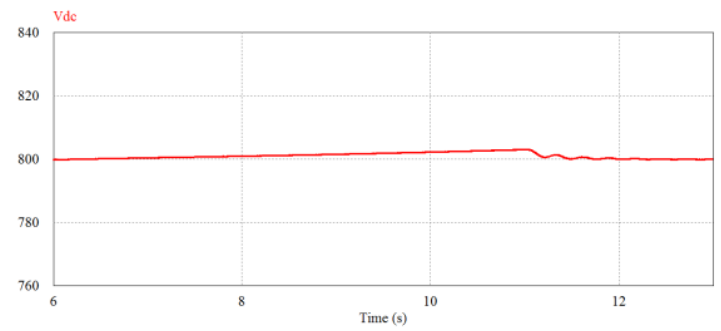

Gambar 20. Tegangan dc link

Pada saat terjadi perubahan kecepatan angin nilai tegangan dc link menjadi naik sedikit lebih dari 800 volt. Akan tetapi pada saat kecepatan angin sudah konstan kembali nilai dc link juga kembali konstan menjadi 800 volt.

\section{Kontrol Daya Reaktif (VAR) pada Grid}

Pada simulasi ini digunakan kecepatan angin konstan yaitu $11 \mathrm{~m} / \mathrm{s}$. Kontrol daya reaktif bertujuan untuk memperbaiki faktor daya pada grid.

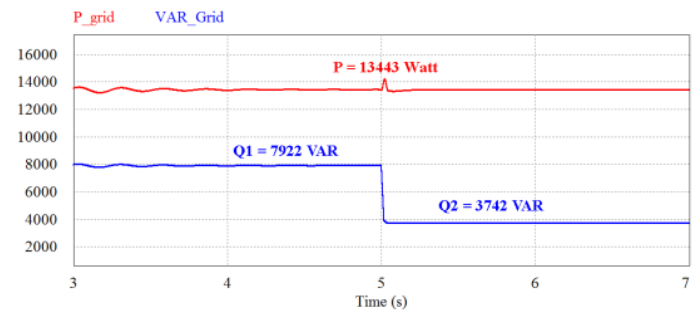

Gambar 21. Daya reaktif pada jaringan listrik

Pada grafik diatas terlihat bahwa pada nilai kecepatan angin dan daya aktif (watt) yang sama nilai daya reaktif yang disuplai ke jaringan listrik berbeda yaitu 7922 VAR kemudian menjadi 3742 VAR pada waktu tertentu. Hal ini menunjukkan bahwa back to back voltage source inverter dapat mengatur besar daya reaktif pada jaringan listrik.

\section{KESIMPULAN}

Dari hasil simulasi dan analisis dapat disimpulkan beberapa hal sebagai berikut:

1. Back to back voltage source inverter dapat mengontrol kecepatan, tegangan dan frekuensi generator induksi serta aliran daya secara dua arah atau bidirectional.

2. Pada pengujian keadaan steady state tegangan, arus, frekuensi pada generator serta tegangan dan arus grid bernilai konstan. Sedangkan pada kondisi dinamik maka nilai dari parameter diatas berubah sesuai dengan kondisi angin.

3. Nilai tegangan dc link dan frekuensi grid bernilai konstan baik pada kondisi steady state dan dinamik kecepatan angin sesuai dengan nilai referensi.

4. Back to back voltage source inverter dapat mengontrol daya reaktif pada grid.

\section{SARAN}

Saran yang diberikan pada penelitian ini adalah:

1. Diperlukan adanya metode untuk menentukan nilai kecepatan turbin angin referensi untuk menghasilkan daya maksimum secara otomatis, karena pada penelitian ini kecepatan turbin referensi didapatkan dari pengujian turbin angin terlebih dahulu. Pencarian nilai kecepatan turbin dapat menggunakan metode artificial intelligence seperti Perturb and Observe, serta firefly.

2. Pada penelitian ini mode operasi sistem adalah grid connected, oleh karena itu pada penelitian selajutnya diusulkan untuk sistem yang dapat bekerja pada operasi grid connected dan stand alone. Pada penelitian selanjutnya dilakukan simulasi islanded atau pada saat grid loss dari sistem dan beberapa saat kemudian grid kembali lagi ke sistem.

3. Back to back voltage source inverter digunakan untuk memperbaiki faktor daya sistem secara otomatis dengan metode kontrol closed loop misal kontrol PI. 


\section{DAFTAR PUSTAKA}

[1] Heri Ardiansyah, "Studi Regulasi Output Generator Induksi dengan Voltage Source Inverter", Proceeding Seminar Tugas Akhir elektro FTI-ITS, ITS, 2012.

[2] Ling Xu, Zhixin Miao, "Control of Back to back VSC System from Grid Connection to Islanded mode in Micro grids", IEEE Confererence, 2013.

[3] Thohaku Abdul Hadi, "Desain dan Simulasi Sistem Pembangkit HIBRIDA PV-WIND Menggunakan Konverter High Gain Integrated Cascade Boost (HGICB) Terhubung Jaringan", Proceeding Seminar Tugas Akhir elektro FTI-ITS, ITS, 2015.

[4] Hadi Malek. "Control of Grid-Connected Photovoltaic Systems Using Fractional Order Operators". Dissertation Electrical Engineering UTAH State University, 2014.

[5] E. Muljadi, C.P. Butterfield, "Investigation of Self-Excited

Induction Generators for Wind Turbine Applications", IEEE Industry Applications Society Annual Meeting, 2000.

[6] A Yudhistira Bondan Satriawisesa, "Pengaturan Tegangan dan Frekuensi Generator Induksi Tiga Fasa Penguatan Sendiri Menggunakan Voltage Source Inverter dan Electronic Load Controller", Proceeding Seminar Tugas Akhir elektro FTI-ITS, ITS, 2013.

[7] Marius Fatu, L. Tutelea, R. Teodorescu, "Motion Sensorless Bidirectional PWM Converter Control with Seamless Switching from power grid to stand alone and back", IEEE, 2007. 